\title{
Analyzing the Impact of Dust Accumulation and Different Cleaning Mechanism on Efficiency of Solar Photovoltaic Panel
}

\author{
Atul Kumar ${ }^{*}$, Srivastava Manish ${ }^{2}$ \\ ${ }^{1}$ Streamingo Solutions Pvt. Ltd, atul.utp@gmail.com \\ ${ }^{2}$ ABES Engineering College Ghaziabad
}

\section{ABSTRACT}

Electricity generation around the world is mainly produced by using non-renewable energy sources especially in the commercial buildings. However, Rooftop solar Photovoltaic (PV) system produced a significant impact on environmental and economical benefits in comparison to the conventional energy sources, thus contributing to sustainable development. Such PV's system encourages the production of electricity without greenhouse gas emissions that leads to a clean alternative to fossil fuels and economic prosperity even in less developed areas. However, efficiency of rooftop solar PV systems depends on many factors, the dominant being geographical (latitude, longitude, and solar intensity), environmental (temperature, wind, humidity, pollution, dust, rain, etc.) and the type of PV (from raw material extraction and procurement, to manufacturing, disposal, and/or recycling) used. During the feasibility analysis of the environment, geographical conditions are keep in well consideration, but the pollution level of the city is always overlooked, which significantly influences the performance of the PV installations. Therefore, this research work focused on the performance of rooftop solar PV installed in one of the most polluted city in India. Here, the loss in power generation of rooftop solar PV has been studied for the effect of deposited dust particles, wind velocity before and after the cleaning of the panels. The actual data has been utilized for the calculation of the energy efficiency and power output of the PV systems. According to the results, it has been concluded that dust deposition, wind speed and pollution level in city significantly reduces the efficiency of solar photovoltaic panel. Hence, an overview of social and environmental impacts of PV technologies is presented in this paper along with potential benefits and pitfalls.

Keywords: Rooftop solar PV; Urban Pollution; Dust; Commercial buildings

\section{Introduction}

Globally, the photovoltaic (PV) market development has been driven by distributed installations due to the reduction in price and rise of feed-in tariff policies. Projection for solar PV growth is expected to be increases from year 2014 (i.e 40,000 MW) to 2018 (i.e $80,000 \mathrm{MW}$ ), which is just double by year 2018, as depicted in Figure $1^{[1]}$.

India, fourth largest energy consuming country after USA, China and Russia is not blessed with abundant fossil fuels or the energy resources. Therefore renewable energy plays a vital role in meeting India's energy demand and improving domestic production by imports. The renewables energy access is expected to increase
54,503 MW 99,617 MW by the end of the year $2022^{[2]}$.India has significant solar energy potential to harness than other techniques due to the geological location. With present schemes and policy, solar energy is also more affordable compared to other renewable energy technologies. It can reduce the costing for the generation of solar power therefore India has aimed to deploying 10,000 MW of grid connected solar power by the year $2017^{[2]}$.

Solar power is the conversion of sunlight to electricity by implementing the photovoltaic effect. The photovoltaic effect depends on photovoltaic technology in which certain materials would produce small amounts

Copyright (C) 2018 Atul Kumar et al.

doi: 10.24294/tse.v1i3.730

EnPress Publisher LLC.This work is licensed under the Creative Commons Attribution-NonCommercial 4.0 International License (CC BY-NC 4.0). http://creativecommons.org/licenses/ by/4.0/ 
of electric current when exposed to light (first noted by a French physicist, Edmund Bequerel, in 1839) $)^{[3]}$. The massive potential of solar energy is almost too hard to grasp, which is why harnessing this Sun's energy for useful purposes has sparked the interest of many scientists for thousands of years. A rooftop solar PV installation on commercial or residential buildings is a photovoltaic system that has its electricity-generating solar panels mounted on the rooftop. Depending on available area for mounting grid connected mounted systems, rooftop system are relatively small in size with the range of 5 to 100 kilowatts compared to ground-mounted solar PV systems with capacities ranging from megawatt to $100 \mathrm{kwp}$. Rooftop solar $\mathrm{PV}$ system consist of photovoltaic (PV) panels, a DC/AC power converter/inverter, racks, mounting fixtures, wiring system and other electrical accessories. It helps in reducing the land requirement, dependencies on grid power lead in increasing solar capacities ${ }^{[3]}$.

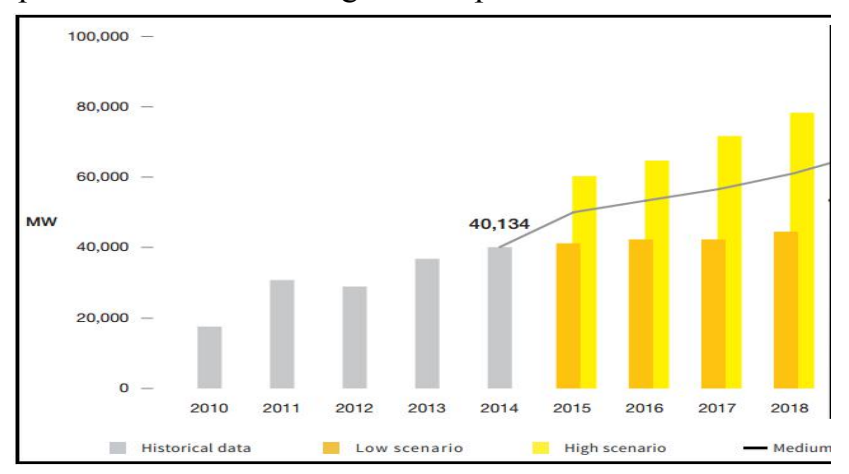

Figure 1; Global annual Solar PV market growth by $2018^{[1]}$

The commercial efficiency of solar power system varies from $17 \%$ to $20 \%{ }^{[4]}$. The name plate rating of solar panel is under standard test conditions; however in actual the working conditions are different. The rooftop PV panels are vulnerable to weather condition, pollution, dust, aerosol, bird dropping, etc., that leads in degrading the PV's performance. By increased wind velocity more heat can be removed from the PV cell surface. In the same vein, higher air lowers the relative humidity of the atmospheric air in the surroundings which in turn leads to better efficiency. On the contrary, wind lifts dust and scatters it in the environment resulting in shading and poor performance of $\mathrm{PV}$ cells ${ }^{[4]}$.Therefore, the research work is focused to study the effect of dust on performance of solar power plant installed on commercial building (Head Quarter of National
Productivity Council), Delhi. Furthermore, this paper also investigates the parameters that lead to the deposition of dust on the solar panel such as wind velocity and urban pollution level.

\section{Study and analysis of Photovoltaic System}

The study and analysis of Solar PV system signifies that the performance and efficiency improvement of photovoltaic system particularly focusing on environmental and weather factors such as the deposition of dust, bird droppings, soiling, snow, etc., on the PV module surfaces that can result in degraded performance and life of such systems.

In order to study the effect of urban air pollution on the energy performance of PV panels, J.K. Kaldellis, A. Kokala conducted an experiment in the densely populated and heavily polluted area, Athens. The results obtained were based on 2 month data for the presence of urban air pollution on the energy yield of PV panels, without cleaning. The PV-panels' energy production was reduced to approximately $6.5 \%$ (in comparison with a clean panel) resulting in annual income loss of almost 40 $\mathrm{V} / \mathrm{kWp}$ which represents $1 \%$ of the current turnkey specific price of domestic PV-generators ${ }^{[5]}$.

The physicists in the field of renewable and sustainable energy investigated the performance of PV module due to dust accumulation and the rate of panel degradation in Oman under laboratory condition using prominent air pollutants (4 type of dust) of different sizes. The sand deposition and fly ash deposition resulted in $4.7 \%$ and $25 \%$ voltage reduction respectively ${ }^{[6]}$. Furthermore, another physicist studied the effects of dust pollution on PV array power output in Saudi Arabia. The experiment conducted by them showed $32 \%$ reduction in output power generation due to desert dust accumulation over the period of eight months ${ }^{[7]}$. Similarly, Due to sand deposition in Kuwait Wakim ${ }^{[8]}$ observed a $17 \%$ reduction in energy efficiency of PV modules after only six days. The power output performance for a year has been studied in the United Arab Emirates by El-Nashar ${ }^{[9]}$ found monthly reductions in glass transmittance by $10 \%$ in summer and $6 \%$ in the winter and overall power output reduction by as much as $70 \%$ over the whole year. Power loss due to haze pollution in Indonesia has been considered before, after and during the haze pollution 
2013 by Maghami et al ${ }^{[10]}$.

Data collected for 8 months for PV performance (voltage, current and temperature) and an environmental condition (temperature, irradiation, air pressure etc) was compared between fixed flat arrays and tracking flat array. The results show that tracking flat photovoltaic more suitable rather than fixed flat. Grassi ${ }^{[11]}$ concluded the reduction in the power output performance of outdoor PV modules after only a few weeks of operation. Elminir et al. ${ }^{[12]}$ investigated the effects of tilt angles on dust deposition and glass transmittance for PV modules. The results showed that more the tilt angle less is the dust deposition density and lower is loss of transmittance. Rate of degradation in PV performance investigated by Beattie et al. ${ }^{[13]}$ found exponential relation with dust accumulation on the free fractional area to the life span of PV module. El-Shobokshy and Hussein $^{[14]}$ studied the effects of the size and density of dust particles on PV performance, and they found that fine dust had a greater effect on PV module performance than coarse dust. Moreover, Goossens and Kerschaever ${ }^{[15]}$ performed air duct experiments to investigate the influence of wind velocity on dust accumulation on PV modules. Their results showed that more energy was lost when the wind velocity raised, due to the greater density of dust deposition on the PV panels.

However, most studies in this area have been focused on the effects of dust pollution for large-scale PV arrays that are mounted on the ground. Few studies have investigated dust accumulation on PV panels that are installed on building roofs especially in densely built polluted urban areas. Investigation to analyses the effect of dust on performance of solar panels under actual installed conditions to study the effect of urban pollution is necessary.

\section{$P V$ Cell Efficiency:}

A variety of factors such as temperature, exposure to sunlight, properties of sunlight, dirt, dust and etc. are efficacious in cell performance ${ }^{[15-16]}$. By increases the solar radiation, $\mathrm{V}_{\text {oc }}$ elevates linearly, as an upshot the resulting power increases. As the cell temperature increases the efficiency drops by lowering the $\mathrm{V}_{\text {oc }}$ and a slight decrease of $I_{\text {sc. }}$. In order to increase the cell efficiency, the cell surface must be kept at lower temperatures and the dirt and dust should be removed from its surface. However, texturing, passivation of the surface and adding anti reflecting materials can improve the performance ${ }^{[16-18]}$.

To maximize the output power and the efficiency of solar cells simply the $\mathrm{V}_{\mathrm{oc}}, \mathrm{I}_{\mathrm{sc}}$ and FF should be boosted up. Likewise while trying to maximize the $I_{1} / I_{s}$ ratio, $I_{s}$ must be kept minimum. Similarly in order to optimize $\mathrm{I}_{1}$, one should maximize the diffusion length and junction width and minimize the reflection of incident photons. The conversion efficiency of the solar cells can be estimated by using Equation 1 such that ${ }^{[16]}$ :

$$
\eta=\frac{I_{s c-\max } \cdot V_{o c-\max }}{A_{c}(\text { irradinace level })}
$$

Besides all the stated parameters, there are some overlooked omnipresent parameters such as deposition of dust, bird droppings, water stains, humidity and wind velocity which can affect solar cell performance and rationally should be taken in to for design of purposes. In this study the effect of dust, humidity and air velocity in terms efficiency will be elaborated.

\section{3. system description and assumptions}

To promote solar energy government of India has devised a policy to provide 30 per cent capital subsidy (sanctioned Rs 50 billion) for rooftop solar installations across residential, government, social and institutional segments. The amount is sufficient to support a total rooftop capacity of 4,200 MW [4]. Grid connected solar plant of $30 \mathrm{kWp}$ was installed at Head Quarter of National Productivity council (NPC), Lodhi Road, New Delhi in January 2015.

Delhi is the second most polluted city in the Asia after Beijing. Dust deposition on the solar panels is a major problem. The normal way to clean the solar panels is to wet wash and wipe or alternatively dry sweep them manually however dust deposition has an acyclic behaviors (due to varied scenario of wind, storm, smog, bird movement, activities in the vicinity etc.) and cleaning schedule is a time bound and cyclic/fixed frequency exercise. Increasing the frequency or ordering an out of schedule cleaning would entail higher operational cost of the plant. Currently the panels are dry cleaned manually, once a week. Wet wash is taken once a month. 


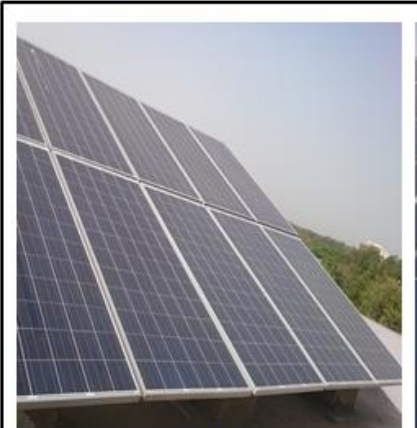

(a)

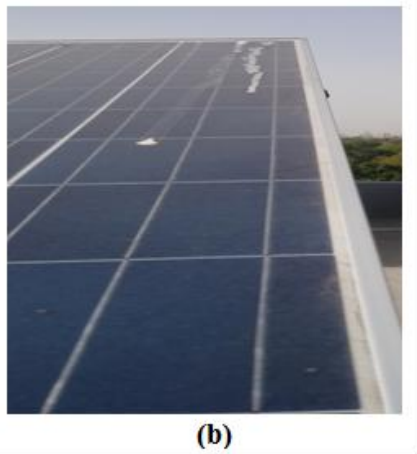

(b)
Figure 2; Installation of Solar panels (a) with dust and (b) with bird dropping.

Based on the above situation (as depicted in Figure 2), real data has been collected from installation site in the month of April' 2016. The purpose of such collection is to estimate the loss in power generation by developing a simple and reliable theoretical analytical model. To build such analytical model, several steps have been considered which includes installation of $300 \mathrm{Wp}$ Titan solar panels, with tilt angel of 28 degree and REFUsol 010K (1), REFUsol 020K+ (1) type invert system. Furthermore, to investigate the loss in power generation, the power generation data and solar radiation data has been collected for 20 days such that:

(i) Firstly, PV's panel has been cleaned well in the beginning of April month, and kept exposed to natural air pollution for 20 days.

(ii) Then, after 15 days, panels have been cleaned again with an iteration of cleaning and estimation of data after 5 days by using the conventional procedure of dry cleaning.

The assumptions and limitations for the analysis comprised the following steps:

During the hourly recording of the power generation by PV-panels under investigation were recorded along with the intensity of solar radiation. Besides that, the ambient temperature, panel temperature and dust level in the city was also considered.

Power generation calculation doesn't consider quantity of dust accumulation and dust factor

It was difficult to obtain spectral distribution and temperature measurements for this study.

The performance and the efficiency of solar PV system varies with change in solar irradiation and ambient temperature. In order to maintain the correctness of experimental and theoretical analysis and to normalize the variation of solar radiation and ambient temperature during the study period, percentage error is calculated using equation (2).

$$
\mathrm{E}_{\mathrm{n}}=\left(\mathrm{E}_{\text {output }}\right) /\left(\mathrm{E}_{\text {basecase }}\right)^{*}(\mathrm{Irr})
$$

where, En normalized energy generated over the period of time is ratio of energy output "P $\mathrm{P}_{\text {output }}$ " of a PV installation normalized to variation of solar radiation to the energy generated during cleaning of PV panels' considered as the base-case scenario.

\section{Experimental setup and analysis}

The power generation data is captured through online monitoring of the system. On the day 1 of the experiment, the panels were cleaned thoroughly using clean cloth, water and again with cloth to remove the dry dust, wet dust and bird dropping. Without cleaning the panels for next 15 days, daily hourly power generation data was capture daily, and cumulated for 5 days each. On the 16th day, panels were again clean to remove the dry dust settled on the panel due to high level of pollution around the site location. From the 16th day after removal of dry dust from panel and power generation data was captured on daily basis and again cumulated for 5 days. The site location and experiment setup is shown in Figure 3 and Figure 4.

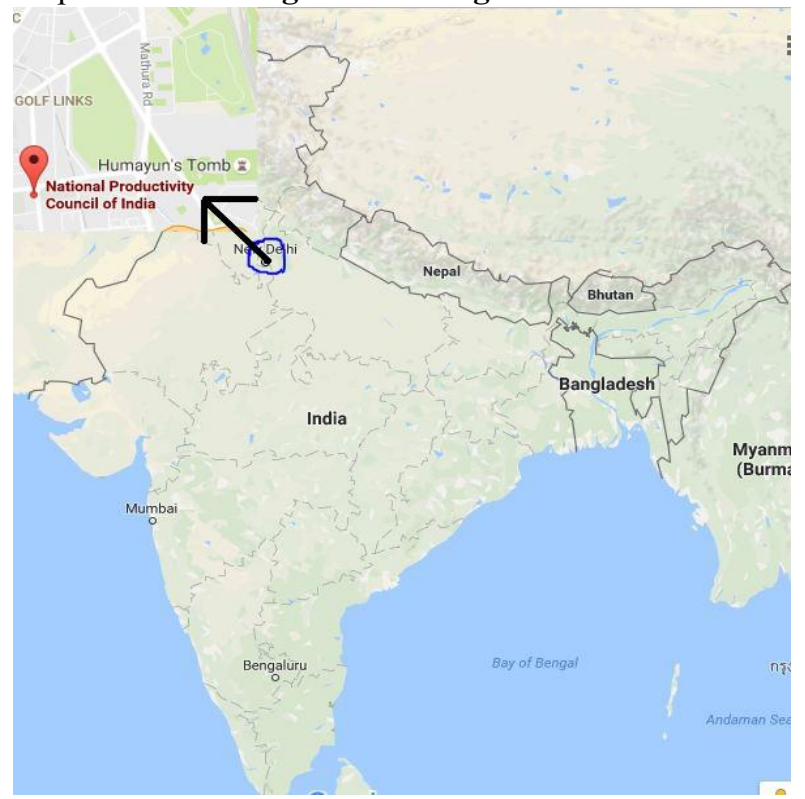

Figure 3; Study location imposed on map of India.

Applying the above presented methodology and assumptions, measurements were conducted for specified time period corresponding to different methods of panel cleaning. The data measurement was conducted from 6:00 am to $6: 00 \mathrm{pm}$, under different atmospheric 
conditions (e.g. ambient temperature, humidity, wind velocity etc.) with the time interval of an hour daily of grid connected solar PV system under experiment. During the recording procedure the values of the power generation by PV-panels, ambient temperature and solar radiation $(\mathrm{W} / \mathrm{m} 2)$ were measured along with panel temperature. The ambient temperature and solar radiation data was collected from Indian Meteorological Department, located at Lodhi Road.

\section{Analysis:}

The power generated, was closely monitored daily and cumulated energy generation for 5 days each was normalized using the equation (4). The Figure 4

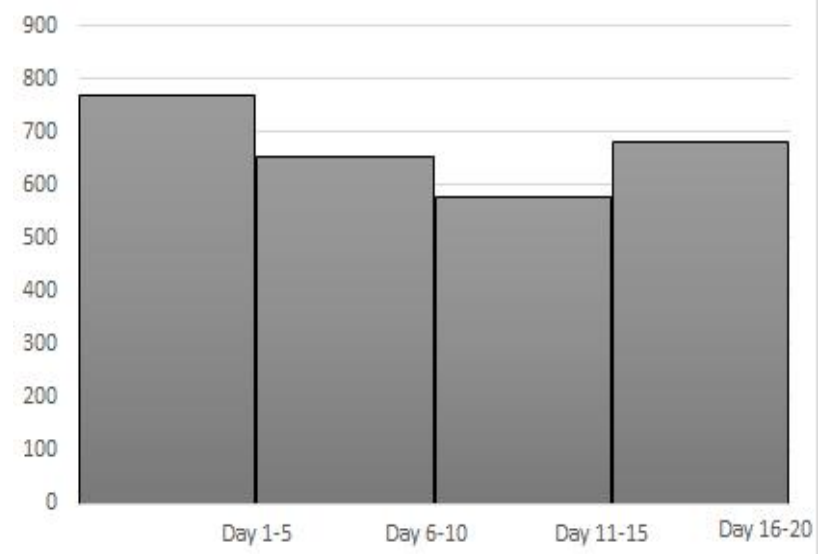

Figure 4; Normalized energy generation over the study period.

Accumulation of dust on solar PVs considerably affects its performance, after 10 days of no cleaning the energy generation reduced by $15 \%$ of the generated energy when panel were properly cleaned, and gradually the generation after 15 days of no cleaning reduced by almost $25 \%$ in the examined case, as the dust deposition density on the panel increases. The analysis also shows, the accumulation of dust derate the performance of PV-generator. On $16^{\text {th }}$ day when panels were again cleaned, the power generation increased and loss in energy was $11 \%$ with respect to the base-case.

As per the Van der Waals adhesive forces theory, the forces between the dust particles are very strong and the accumulated dust tends to stick on panels. Due to wind or light rain the dust on the panels doesn't wipe out, on contrast to this the light rain results in water spots on the panel leading to further accumulation of dust and pollens. The manual cleaning method adopted in most of the rooftop solar PV installed in commercial buildings is conventional and non-effective way to clean the panels.

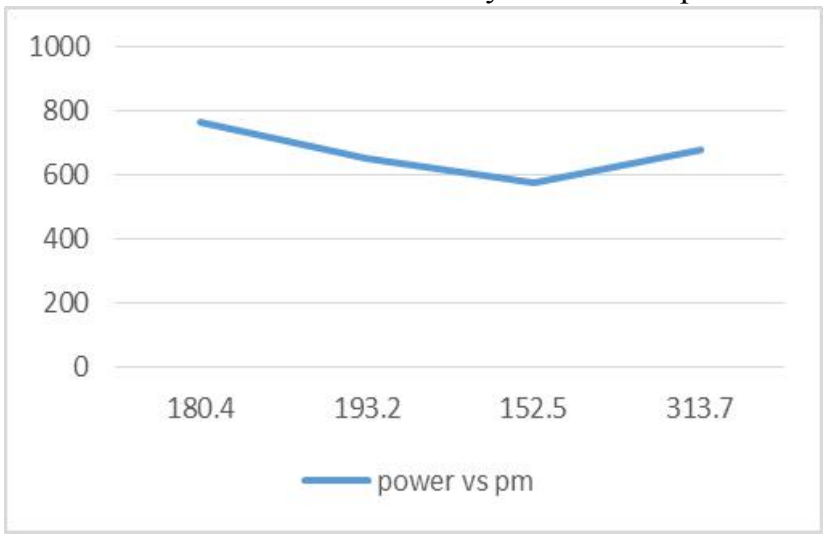

\section{Conclusion}

Effect of dust on the performance of rooftop solar pv system during the month of April was studied in order to estimate the effect of urban air pollution on the energy performance and degradation effect. The actual site data of rooftop solar PV installed on office building with fixed tilt angel of $28^{\circ}$ inclination located in heavily polluted city in India was monitored. According to the results obtained, the progressive deposition of dust on panel reduces power generation by $16 \%$ if kept exposed under urban pollution without cleaning. Incorporating the dry cleaning method of panel for after every 5 days reduces the power generation by $11 \%$ (against $16 \%$ reduction when no cleaning is done). In the study, it was also observed that the dust deposition in heavily polluted environment stick to the panel and dry cleaning alone is not sufficient.

Additional research to estimate the impact of natural air pollution on the energy performance of PVs for a longer period of outdoor exposure, e.g. one year can be considered, so that the influence of certain weather parameters (such as metrological effects, solar spectrum and wind velocity) on the dust accumulation can also be evaluated. Further the urban pollution characteristics such dust particle adhesion, chemical property causing the accumulation of dust deposition and stickiness behavior. The method adopted for cleaning of rooftop solar PV in a commercial buildings to overcome the loss due to dust accumulation is either depends on natural cleaning or mechanical cleaning using water and cloth. Present method is neither effective nor ensure timely and regular cleaning of panels to reduce loss. More investigation and ideas are important pertaining to 
cleaning of small scale solar PV systems installed in buildings to reduce the effect of dust and loss in power generation.

\section{Acknowledgment}

The authors would like to express their deepest appreciation to National Productivity Council, New Delhi and Indian Metrological Department, New Delhi for their technical assistance and support in this study.

\section{References}

1. Global Market Outlook for Solar Power 2015-2019, EPIA - European Photovoltaic Industry Association. 9 June 2015

2. Vivek Mehra, Twelfth Five Year Plan (2012-2017), Planning Commission, Govt. of India, 2013, SAGE publication, New Delhi, India.

3. TERI Energy \&amp; Environment Data Diary and Yearbook, 2014, p.400,

4. Mekhilef S., Saidur R, and Kamalisarvestani M., "Effect of dust, humidity and air velocity on efficiency of photovoltaic cells", Renewable \&amp; Sustainable Energy Reviews, Vol. 16, No. 5, pp. 2920-2925, 2012.

5. Hussein A Kazem, Chaichan MT, Al-Shezawi IM, Al-Saidi HS, AlRubkhi HS, Al-Sinani JK and Al-Waeli AHA, "Effect of Humidity on the PV Performance in Oman", Asian Transactions on Engineering, Vol.2, No.4, pp: 29-32, 2012.

6. Kaldellis JK.,Kokala A, "Quantifying the decrease of the photovoltaic panels' energy yield due to phenomena of natural air pollution disposal", Energy, Vol. 35, pp. 4862-4869, 2010.

7. Hussein A Kazem, "Effect of Dust Deposition on the Performance of Multi-Crystalline Photovoltaic Modules Based on Experimental Measurements", International Journal of Renewable Energy Research, Vol.3, No.4, 2013.

8. Salim AS., Atul Kumar Singh, Miros Maroof, MM., Mohd A. Bou-Rabee, "Influence of Dirt Accumulation on Performance of PV Panels, Technologies and Materials for Renewable Energy, Environment and Sustainability, Vol. 50, pp. 50-60, 2014.

9. Wakim F., "Introduction of PV power generation to Kuwait", Kuwait: Kuwait Institute for Scientific Research, Report no. 440, 1981.

10. El-Nashar AM., "The effect of dust accumulation on the performance of evacuated tube collectors", Solar Energy, Vol. 53, No.1, pp.105-115, 1994.

11. Maghami M, Hizam H, Gomes C, Hajighorbani S, Rezaei N., "Evaluation of the 2013 Southeast Asian Haze on Solar Generation Performance", . PLOS one, Vol.10, No.8, e0135118, 2015.

12. Grassi G., "Two-year experience of the EC photovoltaic pilot projects", In: Proc 18th IEEE photovoltaic specialist's conf., Las Vegas, USA, pp.871-875, 1985 .

13. Elminir HK, Ghitas AE, Hamid RH, El-Hussainy F, Beheary MM, Abdel-Moneim KM., "Effect of dust on the transparent cover of solar collectors", Energy Convers Manage, Vol. 47, Issues 18-19, pp.3192-3203, 2006.

14. Beattie NS, Moir RS, Chacko C, Buffoni G, Roberts SH, Pearsall NM., "Understanding the effects of sand and dust accumulation on photovoltaic modules", Renew Energy, Vol.48, pp.448-452, 2012

15. Mekhilef S, Saidur R, Safari A., "A review on solar energy use in industries", Renewable and Sustainable Energy Reviews, Vol. 15, No. 4, pp.1777-1790, 2012.

16. Iyengar VV., Nayak BK., Gupta MC., "Silicon PV devices based on a single step for doping, anti-reflection and surface passivation", Solar Energy Materials and Solar Cells, Vol.94, Issues 12, pp. 2205-2211, 2010.

17. El-Shobokshy MS., Hussein FM., "Effect of the dust with different physical properties on the performance of photovoltaic cells", Solar Energy, Vol.51, No.6, pp.505-511, 1993.

18. Jiang H, Lu L, Sun K., "Experimental investigation of the impact of airbourne dust deposition on the performance of solar photovoltaic (PV) modules", Atmospheric Environmen, Vol.45, No.25, pp.4299-4304, 2011. 